\title{
Editorial: Mountain Building
}

\author{
György Hetényi ${ }^{1 *}$, A. Alexander G. Webb ${ }^{2}$ and Mark R. Handy ${ }^{3}$ \\ ${ }^{1}$ University of Lausanne, Lausanne, Switzerland, ${ }^{2}$ The University of Hong Kong, Pokfulam, Hong Kong, SAR China, ${ }^{3}$ Freie \\ Universität Berlin, Berlin, Germany
}

Keywords: orogeny (formation of mountains), scales, geological processes, geophysical imaging, earthquakes, modelling

\section{Editorial on the Research Topic}

\section{Mountain Building}

Mountain building involves the interaction of numerous geological processes that operate on a broad spectrum of spatial and temporal scales. Mountains themselves are geo-archives that preserve the traces of these processes. They document the history of plate boundaries, from the rifting of continents, the spreading and closure of oceans, to the partial subduction and collision of continental lithosphere. Mountains provide a glimpse of how processes shaping the surface interact with crustal structure, including structures that pre-date orogenesis. Rocks exposed in mountains allow us not only to constrain the rates of subduction, metamorphism and exhumation, but also to estimate rates of erosion and surface uplift. Geophysical images of the depths beneath mountains contribute to our understanding of how lower crust, lithospheric mantle and asthenosphere behave during orogenesis. Together with modelling studies, these observations are changing notions on the formation of natural resources and on assessing natural hazards such as earthquakes.

The papers in this volume represent a step forward in understanding how mountain-building processes at the surface affect deep-seated processes, and vice-versa. The prime challenge of this multidisciplinary endeavour is to fill gaps in our knowledge of Earth's 3-D structure, as well as in the record of motion of rock bodies back in time, the fourth dimension. For young orogens, filling the gaps requires complementary datasets from the surface and subsurface. The former come from field-based studies that quantify source-to-sink paths of eroded rocks and the kinematics of subducted and exhumed basement rocks. The latter derive from geophysical imaging of rock bodies with contrasting physical properties such as density, seismic velocities and their anisotropy, electrical conductivity and fluid content. Deeply eroded orogens are natural laboratories for such studies, because their exposures of all levels of the crust, from unmetamorphosed sediments to the lower crust, provide clues to understanding ongoing processes in active orogens.

The contributions below deal with the structure of the Alpine-Himalayan mountain belt. The Alps in particular are a time-honoured testing ground for ideas on mountain building. Asthenospheric flow beneath the Alps revealed by new seismic anisotropy studies varies with depth and records intricate flow patterns around sinking slabs and through gaps in these slabs formed by tearing (Link and Rümpker 2021). The overlying orogenic crust is equally complex, especially in the arc of the Western Alps where new joint inversion of gravity and seismological data yield a refined 3-D geometric view of the famous Ivrea Geophysical Body. There, the lithospheric mantle rises to within only a few $\mathrm{km}$ of mantle rocks exposed at the surface (Scarponi et al., 2021). The Alpine Moho appears to be sensitive to local variations in the composition of the (pre-)orogenic crust, as studied in the eastern Southern Alps at its junction with the Dinarides (Sadeghi-Bagherabadi et al., 2021), a site of slow (1-2 mm/yr) Adria-Europe plate convergence. Fault activity at this complex orogenic knot involves episodic fault-valve 
behaviour due to the recurrent release of pore pressure trapped in the vicinity of faults that juxtapose rocks with contrasting permeability (Rossi et al., 2021).

The Himalayas are home to the largest continent-continent collision on Earth, forming an orographic and climatic barrier, as well as structural anomaly of the first order. Like the Alps, they show strong lateral (along-strike) variations in orogenic structure, particularly as expressed by crustal and upper mantle thickness (Kumar et al., 2021). At the surface, this variation may be manifested by a subdivision of the orogen into segments with different thrust geometries and separated by so-called cross faults (Hubbard et al., 2021). These faults delimit areas of distinctive seismicity and themselves coincide with zones of enchanced seismicity. A particularly active, deep-crustal fault zone marking the eastern edge of the underthrusting India plate (the Dhubri-Chungthang Fault zone) is connected to a cluster of intermediate-depth (ca. $70 \mathrm{~km}$ ) seismicity in Southern Tibet. This cluster had been scrutinized by Michailos et al. (2021) with implications for both tectonic and metamorphic processes. On the northern margin of the Tibetan Plateau, variations in the thickness of salt layers in the orogenic foreland are important determinates of the geometry of nappes, as modelled in the foreland thrust-and-fold belt of the Tarim Basin (Li et al., 2021). Along-strike variation in subsurface structure is also manifested in the physical properties of the Himalayan orogenic wedge, as revealed in western and eastern Bhutan by global phase seismic interferometry (Obermann et al., 2021). Surface ruptures, for example, from the Mw 8.1 1714 Bhutan earthquake, suggest that stress is transferred both to the foreland, favouring in-sequence thrusting (Zhao et al., 2021), as well as upward, possibly triggering normal faulting and extension of the orogenic wedge. Indeed, detailed studies of seismic swarms on a normal fault in the hangingwall of the Main Central Thrust following the $2015 \mathrm{Mw} 7.8$ Gorkha earthquake, Nepal, may be diagnostic of orogenic collapse and stress

\section{REFERENCES}

Adhikari, L. B., Bollinger, L., Vergne, J., Lambotte, S., Chanard, K., Laporte, M., et al. (2021). Orogenic Collapse and Stress Adjustments Revealed by an Intense Seismic Swarm Following the 2015 Gorkha Earthquake in Nepal. Front. Earth Sci. 9, 659937. doi:10.3389/feart.2021.659937

Furlong, K. P., Kirby, E., Creason, C. G., Kamp, P. J. J., Xu, G., Danišík, M., et al. (2021). Exploiting Thermochronology to Quantify Exhumation Histories and Patterns of Uplift along the Margins of Tibet. Front. Earth Sci. 9, 688374. doi:10.3389/feart.2021.688374

Hubbard, M., Mukul, M., Gajurel, A. P., Ghosh, A., Srivastava, V., Giri, B., et al. (2021). Orogenic Segmentation and its Role in Himalayan Mountain Building. Front. Earth Sci. 9, 641666. doi:10.3389/feart.2021.641666

Kumar, A., Kumar, N., Mukhopadhyay, S., and Klemperer, S. L. (2021). Tomographic Image of Shear Wave Structure of NE India Based on Analysis of Rayleigh Wave Data. Front. Earth Sci. 9, 680361. doi:10.3389/ feart.2021.680361

Li, C., Yin, H., Wu, Z., Zhou, P., Wang, W., Ren, R., et al. (2021). Effects of Salt Thickness on the Structural Deformation of Foreland Fold-And-Thrust Belt in the Kuqa Depression, Tarim Basin: Insights from Discrete Element Models. Front. Earth Sci. 9, 655173. doi:10.3389/feart.2021.655173 change involving the migration of $\mathrm{CO}_{2}$-rich fluids (Adhikari et al., 2021). This post-rupture swarm seismicity may have been enhanced by seasonal variations in the nearsurface hydrological load. Earth's surface, particularly its temperature history, is a sensitive recorder of heat advection and cooling during exhumation and surface uplift. Thermochronometry applied to high-relief ranges along the eastern margin of the Tibetan Plateau shows that exhumation related to India-Asia convergence began in late Paleogene time, then accelerated intermittently throughout Neogene time to rates as high as $2 \mathrm{~mm} / \mathrm{yr}$ along major reactivated thrusts in the central Longmen Shan (Furlong et al., 2021).

The diversity of contributions in this volume serve to emphasize Alfred Wegener's (1880-1930) prescient words on Earth Science (paraphrased in translation by M.H.): "Only by integrating all Earth Sciences can we hope to approach truth, i.e., to arrive at a picture that arranges known facts in a way that can be said to have the greatest probability of explaining our observations". These words hold as much today as when they were first written and ushered in a new way of looking at mountains and how they form.

\section{AUTHOR CONTRIBUTIONS}

All authors listed have made a substantial, direct and intellectual contribution to the work, and approved it for publication.

\section{ACKNOWLEDGMENTS}

We are grateful to all reviewers for their time, care and contributions to the manuscripts published in this special volume. We also thank the editorial team as well as the Frontiers team for their support throughout the process of assembling and publication.

Link, F., and Rümpker, G. (2021). Resolving Seismic Anisotropy of the LithosphereAsthenosphere in the Central/Eastern Alps beneath the SWATH-D Network. Front. Earth Sci. 9, 679887. doi:10.3389/feart.2021.679887

Michailos, K., Carpenter, N. S., and Hetényi, G. (2021). Spatio-Temporal Evolution of Intermediate-Depth Seismicity beneath the Himalayas: Implications for Metamorphism and Tectonics. Front. Earth Sci. 9, 742700. doi:10.3389/ feart.2021.742700

Obermann, A., Ruigrok, E., Bianchi, I., and Hetényi, G. (2021). Constraining the Moho Depth below Bhutan with Global-phase Seismic Interferometry. Front. Earth Sci. 9, 658146. doi:10.3389/feart.2021.658146

Rossi, G., Pastorutti, A., Nagy, I., Braitenberg, C., and Parolai, S. (2021). Recurrence of Fault Valve Behavior in a Continental Collision Area: Evidence from Tilt/ Strain Measurements in Northern Adria. Front. Earth Sci. 9, 641416. doi:10.3389/feart.2021.641416

Sadeghi-Bagherabadi, A., Vuan, A., Aoudia, A., and Parolai, S.AlpArray-Swath-D Working Group (2021). High-Resolution Crustal S-Wave Velocity Model and Moho Geometry beneath the Southeastern Alps: New Insights from the SWATH-D Experiment. feart 9, 641113. doi:10.3389/feart.2021.641113

Scarponi, M., Hetényi, G., Plomerová, J., Solarino, S., Baron, L., and Petri, B. (2021). Joint Seismic and Gravity Data Inversion to Image Intra-crustal Structures: The Ivrea Geophysical Body along the Val Sesia Profile (Piedmont, Italy). Front. Earth Sci. 9, 671412. doi:10.3389/feart.2021.671412 
Zhao, Y., Grujic, D., Baruah, S., Drukpa, D., Elkadi, J., Hetényi, G., et al. (2021). Paleoseismological Findings at a New Trench Indicate the 1714 M8.1 Earthquake Ruptured the Main Frontal Thrust over All the Bhutan Himalaya. Front. Earth Sci. 9, 689457. doi:10.3389/feart.2021.689457

Conflict of Interest: The authors declare that the research was conducted in the absence of any commercial or financial relationships that could be construed as a potential conflict of interest.

Publisher's Note: All claims expressed in this article are solely those of the authors and do not necessarily represent those of their affiliated organizations, or those of the publisher, the editors and the reviewers. Any product that may be evaluated in this article, or claim that may be made by its manufacturer, is not guaranteed or endorsed by the publisher.

Copyright (c) 2021 Hetényi, Webb and Handy. This is an open-access article distributed under the terms of the Creative Commons Attribution License (CC $B Y)$. The use, distribution or reproduction in other forums is permitted, provided the original author(s) and the copyright owner(s) are credited and that the original publication in this journal is cited, in accordance with accepted academic practice. No use, distribution or reproduction is permitted which does not comply with these terms. 